\title{
如何在高中数学教学中展开高效的高考总复习教学指导工作
}

鲍金凤

安徽省泗县第一中学

DOI:10.32629/jief.v2i4.1148

[摘 要] 在当前的高中教学环境下, 教师在展开数学教学的过程中不仅仅需要能够注重学生基础知识水平的强化教学, 同时还需要能够充分 地注重学生科学素养的培养与提升, 教师在展开高中数学的教学过程中必须要能够充分地结合高考基本要求来展开对学生的复习教学进程, 这样学生才能够在高考过程中取得优异的成绩。本文先简单介绍了高中数学高考总复习指导的基本现状，然后针对当前的现状提出了一些有 效的改善措施。

[关键词] 高中数学; 教学指导; 基础内容; 反思学习; 教材内容 中图分类号: G633.6 文献标识码：A

随着当前社会环境的不断变化, 教师在展开对学生的高中数学教学 过程中必须要能够充分地注重学生基本技能的提升, 而数学学科作为与 生活实践密切联系的综合性学科, 教师在展开教学时必须要能够充分地 注重学生课堂综合效率的提升。

\section{1 高中数学高考总复习教学指导基本现状}

在当前的高中数学教学过程中, 很多教师在展开数学总复习教学时 因为受到以前教学观念的影响。因此在教学时习惯借助于大量的试题来 展开对学生的训练教学模式。

这就导致了学生在高中数学总复习过程中只能够机械化地展开相关 知识的吸收, 这就导致了学生在高中数学学习过程中逐渐地产生庈倦的 消极学习心态, 进而造成了学生在高中数学学习过程中复习效率的降低。 同时还有很多教师在教学时没有充分地结合学生的具体学习状况来展开 复习教学, 这就造成了很多学生在高中数学复习过程中无法有效地展开 对基础内容的学习, 在复习过程中无法形成完善的复习框架, 这在一定 程度上严重限制了学生高中数学学习效率的提升。

\section{2 展开高效高中数学总复习教学指导的有效策略}

2.1 注重对学生基础内容的强化教学

教师在展开高中数学高考总复习的教学过程中想要有效地保证教学过 程的高效性, 就必须要能够在教学时对高考总复习的基础内容展开详细的理 解, 然后再根据复习的主体内容来确定出合理的课堂复习教学计划。

比如教师在展开对高三阶段学生的数学复习教学过程中就可以在教 学时结合复习内容中包含的基础知识框架来展开系统化的教学, 教师可 以在教学时积极地引导学生展开对数学内容的分类复习, 可以将数学的 复习内容划分为代数部分以及几何部分, 然后教师就可以进一步地引导 学生展开对各部分内容的对比式复习。此外, 教师在展开高中数学的高 考总复习教学时还需要能够及时地对学生已经掌握的内容进行回顾式强 化教学, 让学生可以在复习过程中进一步地加深对相关内容的理解。而 且教师在教学时也可以将复习内容中包含的重难点信息进行总结, 然后 就可以要求学生展开深入式理解, 这样学生就能够在高中数学学习过程 中逐渐地提升自己的理解能力。

2.2 针对考题类型展开深入理解

教师在展开高中数学的高考总复习教学指导过程中想要进一步地提 升学生的课堂复习效率, 还需要能够在教学过程中充分地结合当前教学 环境的变化来不断地改善自己的教学理念以及基本的教学方式。教师在 复习教学过程中要能够积极地展开对以往高考内容的深入理解, 然后在 复习过程中要能够展开目标式的复习指导。比如近年来高考大纲中对参 数方程有着越来越高的要求, 教师就可以在教学时充分地结合与参数方
程相关的基础内容以及这部分内容涉及的一些基础内容来展开目标式教 学, 这样学生就可以更加有效地提升自己的高考复习效率。

\section{3 注重学生反思学习能力的提升}

教师在展开高中数学的高考复习教学时还必须要能够充分地注重学 生在学习过程中反思能力的提升, 因为在高中阶段的数学内容中包含了 很多复杂的知识内容, 但是高中数学的教学时间却是极为有限的, 因此 教师必须要能够在教学时积极地引导学生展开对复习内容的反思学习, 让学生可以在复习过程中及时地对学习内容展开反复思考, 这样学生就 能够在复习过程中逐渐地形成完善的复习框架。比如教师在展开 “直线 与圆” 这部分内容的复习时, 教师就可以在教学时引导学生展开对相关 内容的对比理解, 让学生可以对其中包含的差异内容展开反思思考。这 样学生就能够更加有效地提升自己的学习能力。

2.4 充分结合教材内容展开高考总复习教学

学生在高中阶段需要学习的教材内容量是极其巨大的。而大部分教 师在展开高中数学的高考复习教学时并没有能够充分地注重教材基础内 容, 只是在教学时将大量的时间用于对一些复习资料的收集上, 但这样 的复习方式只会导致学生在高考复习学习过程中无法有效地提升自己对 基础概念内容的理解能力, 进而造成了学生无法在高考复习过程中有效 地拓展自己的思维范围, 这对于学生数学水平的提升有着极大的限制作 用。因此教师在教学时必须要能够积极地改善自己的复习教学方式, 在 教学时要能够积极地引导学生展开对教材内容的理解, 让学生可以有效 地提升自己的数学基础水平。

\section{3 结束语}

总而言之, 教师在展开高中数学的教学过程中必须要能够充分地注 重对学生高考总复习教学指导过程的优化。教师在教学时要能够充分地 结合学生的基础学习内容来展开对学生的强化教学。同时, 教师还需要 能够在教学过程中积极地引导学生展开反思, 让学生可以进一步地提升 自己的数学学习能力。此外, 教师在教学时还可以充分地结合教材内容 来进一步地提升学生的高考复习效果, 让学生可以从根本上提升自己的 数学综合水平。

\section{[参考文献]}

[1] 李代鹏. 问题教学法在高中数学中的实践研究 [J]. 名师在 线,2020(24):44-45.

[2] 邱春亮. 基于探究能力培养的高中数学教学 [J]. 数理化解题研 究,2020(24):9-10.

[3] 李海涛.高等数学知识在高中导数教学中的应用 [J].数理化解题 研究,2020(24):13-14. 